the 12000 dives surveyed by us included episodes of rapid or uncontrolled ascent. For what it is worth, we have anecdotal reports of six diving incidents relating to asthmatic divers-four in which there were rapid ascents and two in which divers developed bronchospasm underwater. In all of these cases the divers concerned surfaced safely.

As medical examiners who dive we make it our business to discuss with our clients the examination, the implications of any abnormal findings, and any possible theoretical risks. We believe that this approach is adequate for medicolegal purposes.

It would seem reasonable to advise people with well controlled asthma who wish to dive that they may do so as long as they understand the theoretical risks. The real risk, if in practice there is one, would seem slight according to currently available data. Therefore the British Sub-Aqua Club's current recommendations seem adequate.

PETER GLANVILL PATRICK FARRELL

Deron $\mathrm{EX} 122 \mathrm{KY}$

\section{Should radiologists talk to patients?}

SIR, - In answer to the question posed by Drs Stephen R Vallely and J O Manton Mills' - of course radiologists should talk to patients. I hope that the days are long gone when we were seen as mere technicians, carrying out the requests of our clinical colleagues. Although patients may be in our care for only a relatively short time, for those few minutes they are entirely our responsibility and we should tell them anything that we think it would be in their interests to know. There is no good reason why the radiologist should feel more constrained in this respect than any other consultant talking to an outpatient.

General practitioners seem content for us to do this. When I asked 75 general practitioners in the catchment area of my previous hospital how they felt about radiologists imparting information to their patients the results were encouraging. Forty per cent were happy for the result to be given as a matter of course, $30 \%$ if the patient asked a direct question, and $22 \%$ only if it was good news. Only $6 \%$ said that under no circumstances should the radiologist divulge any information to the patient.

It would be a foolhardy radiologist who forced information on to an unwilling patient, but equally it would be an unrealistic general practitioner or hospital clinician who expected us to say nothing to a worried patient during the course of a 20 minute ultrasound examination or barium study. To take just one example, a woman referred with bleeding in early pregnancy may well know that she is being scanned to see if her baby is alive or dead - to send her away still wondering would be a cruel act of professional negligence. It goes without saying that if a radiologist is in the position of having to give a patient bad news the referring clinician should be informed without delay, usually by telephone, so that he or she is in full possession of the facts before seeing the patient.

R F BURY

Leeds I.S8 2JX

1 Vallely SR, Mills JOM. Should radiologists talk Io patients? Br.Med f 1990;300:305-6. 3 February.

SIR,-Drs Stephen R Vallely and J O Manton Mills showed quite conclusively that in general patients wish to know the results of radiological investigations immediately ( 269 patients wanted to know compared with five who did not) but that clinicians are reluctant for the patients to be told of findings that indicate malignancy.
We disagree with the authors' recommendation that when malignancy is diagnosed or strongly suspected radiologists should indicate that they will discuss the result with the clinician. The patient knows that the radiologist is already aware of the result of the investigation. If, as Drs Vallely and Mills suggest, categorical reassurance is provided when no malignancy is found, then lack of this reassurance will alert the patient to sinister findings and cause the anxiety that the authors are so keen to avoid. To suggest that the radiologist tells the patient that the result needs to be discussed with the referring clinician will also cause anxiety and invariably lead to direct questions from the patient. If radiologists are to maintain credibility with the public they must answer these questions truthfully.

There will always be some patients whom the referring clinician does not want informed of any bad news, and we suggest that this is clearly indicated on the request form. We agree that most radiology departments are not usually the ideal setting for giving bad news, but most radiologists are capable of communicating information about cancer honestly, compassionately, and immediately - thereby removing the dreadful and unnecessary time of uncertainty for the patient.

MARK CHARIG

Department of Radiology

Churchill Hospital

Oxford OX37LJ

1 Vallely SR, Mills JOM. Should radiologists talk to patients? BrMed f 1990;300:305-6. (3 February.)

\section{Variations in reported serum alkaline phosphatase activities}

SIR, - Dr D P Addy's frustration at the variations in reported serum alkaline phosphatase activities among laboratories' is understandable, but the suggestion that the clinical chemists should get their act together is misdirected. The clinical chemists have had their act together for some years, and reports of the variations in precision and accuracy within and among laboratories are freely available.

The interlaboratory variation in serum alkaline phosphatase measurement in the United Kingdom was reported in 1977 to be $15-32 \% .^{2}$ Though this is high, it is not as high as the twofold variation suggested by Dr Addy. Perhaps more importantly, modern methods of serum alkaline phosphatase measurement are capable of fine precision, and variation within laboratories is small. ${ }^{3+}$

The reason for the wide variation in alkaline phosphatase activity reported by different laboratories apparently using the same units lies in the definition of the international unit, which is simply the amount of enzyme that forms one micromole of product per minute. This definition makes no allowance for methodological differences such as substrate concentration and $\mathrm{pH}$. The solution to the frustration caused by this apparent ambiguity lies in the laboratories' reference ranges. I recommend the simple procedure of converting each measurement into a percentage or multiple of the reporting laboratory's upper reference limit. ${ }^{5}$ Thus a value of 0.5 would mean half the upper reference limit, $2 \cdot 0$ would mean twice the limit, and so on. By this means, at least some of the difficulties of comparing enzyme measurements from different laboratories may be relieved.

INO Institute for Experimental Gerontology,

S G PARKER

PO Box 5815

2288 HV Rijswijk,

The Netherlands

1 Addy DP. Variations in reported serum alkaline phusphatase activities. Br.Med 7 1990;300:116. (13 January.)
2 Whitchead TP. Qualty control in clinical chemistry. New York John Wiler, 1977:34

Cornish CJ, Neale FC, Posen S. An automated fluorimetric alkaline phosphatase microassay with 4-methylumbellifery phosphate as substrate. American foumal of Chemical Patholog 1970;56:68-76.

+ Burnett RW. Accurate estimations of standard deviations for yuantitative methods used in clinical chemistry. Clin Chem 1975:21:1935-8.

5 McComb RB, Bowers NB, Posen S, eds. Alkaline phosphatase. New York: Plenum Press, 1979:527.

\section{Why are the Japanese living longer?}

SIR, - In their report Professor M G Marmot and Dr George Davey Smith write that the fact that the Japanese have the longest life expectancy in the world is based on the success of the Japanese economy, the organisation of work in Japan, a well functioning public health system, and the Japanese diet. As a Japanese doctor I would like to emphasise the importance of the health system and diet.

The increase in life expectancy in Japan until the 1960 s was contributed to by the decrease in both infant mortality and the number of cases of tuberculosis. The recent increase in life expectancy in Japan has been influenced by the decrease in mortality in men in their 70 s and women in their $70 \mathrm{~s}$ and $80 \mathrm{~s}$, which has been mainly brought about by the decrease in mortality caused by cerebrovascular disease or stroke.

Malignant tumours, cardiovascular disease, and stroke are three cardinal causes of death in Japan in decreasing order of incidence. As Professor Marmot and Dr Smith observed, people visiting Japan from the West find it difficult to eat their normal high fat diet. The low fat diet in Japan has contributed to the low prevalence of cardiovascular disease among Japanese people.

The Japanese used to have an extremely high salt intake, giving rise to high blood pressure and stroke. Consumption of salt has decreased in recent years in Japan because of public health education on the aetiology of hypertension, and in turn the incidence of stroke as a main cause of death has decreased.

Japanese life expectancy in the future, however, is not necessarily bright as Japanese people have recently started eating a diet that has a higher saturated fat content than before.

TSUTOMU SAKUTA

Department of Psychiatry and Neurology,

Keio University Hospital,

Tokyo 160 ,

Japan

1 Marmot MG, Smith GD. Why are the Japanese living longer? Br.Med f 1989;299:1547-51. (23-30 December.)

\section{Nibblers, gorgers, snackers, and grazers}

SIR, - We thank Professor D A T Southgate for his editorial' ${ }^{1}$ on our work. As he made clear, the aim of our paper was to explore the metabolic effects of spreading the nutrient load. It was Professor Southgate, however, who introduced this concept nearly 20 years ago as an extension of the dietary fibre hypothesis. He suggested that fibre might reduce the rate of absorption by reducing the rate of diffusion of the products of digestion towards the absorptive mucosal surfaces.

His suggestion has been confirmed by subsequent studies, which showed both in vivo and in vitro that viscous fibres such as guar and pectin prolong carbohydrate and amino acid absorption and reduce the rate of starch digestion. ${ }^{3+}$ Although gastric emptying may play a part in this process, direct intubation showed the importance of fibre in impeding diffusion of glucose through the contents 